\title{
Mucormycosis in COVID-19: Is Zinc a Silent Killer in India?
}

\author{
Sayan Nath ${ }^{1}$, Dalim K Baidya ${ }^{2}$ (우 \\ Keywords: COVID-19, Mucormycosis, Zinc. \\ Indian Journal of Critical Care Medicine (2021): 10.5005/jp-journals-10071-23938
}

The second wave of coronavirus disease 2019 (COVID-19) in India has hit the country hard with over 6.6 million people infected just in the month of April 2021.' Recently, a particular concern in COVID-19-affected patients has been the rising incidence of mucormycosis. $^{2}$

The estimated prevalence of mucormycosis in India is around 70 times higher than the rest of the world. Diabetes mellitus is the most common risk factor, followed by hematological malignancy and solid organ transplant. ${ }^{3}$ The immune dysregulation due to reduced numbers of $T$ lymphocytes, CD4+T, and CD8+T cells in COVID-19 may alter the innate immunity that facilitates opportunistic fungal growth in these patients. The recent surge in cases of mucormycosis has been linked to rampant usage of corticosteroids, hyperglycemia, broad-spectrum antibiotics, and monoclonal antibodies on a background of an already suppressed immune system in these patients. ${ }^{4}$ However, one particular factor that has been commonly overlooked is the uncontrolled and unmonitored use of zinc in COVID-19. Zinc, which was initially thought to be helpful in the prevention and treatment of COVID-19 owing to the hypothesized antiviral activity, was later found to be ineffective for the same. ${ }^{5}$ Long-term use of large doses of zinc has concerns of serious adverse effects like copper deficiency and neurological deficits, and major guidelines have recommended against the use of zinc in doses above its recommended dietary allowance for the treatment of COVID-19. ${ }^{6}$ However, many regional guidelines in India continue to include high dose zinc as a common treatment across several categories of COVID-19. ${ }^{7,8}$ Zinc being available as an over the counter medication has facilitated general population to consume it in large quantity with hope of protection against COVID-19 due to widespread circulation of such guidelines through social media.

Zinc is known as a common growth factor for different pathological fungi, including Mucorales. ${ }^{9}$ Zinc influences diverse mechanisms of fungal pathogenesis by directly regulating fungal proteins required to infect mammalian hosts. ${ }^{10}$ Zinc deprivation by the host is an important antifungal mechanism, ${ }^{11}$ and zinc chelators have been shown to inhibit different fungal growth, including Mucorales, both in vitro and in vivo. ${ }^{12,13}$ It is possible that the excess availability of zinc in the body owing to its incessant use by COVID- 19 patients might be adding to the risk of fungal infections like mucormycosis in these patients.

To determine whether Zinc has a constant and significant association with mucormycosis in COVID-19-affected patients, further studies are needed. But since zinc is a definite facilitator of fungal infection, in the absence of its clear-cut benefit against the COVID19 disease, authorities and expert panels in India should read out words of caution and raise awareness against rampant usage of high
1,2Department of Anaesthesiology, Pain Medicine and Critical Care, All India Institute of Medical Sciences, Delhi, India

Corresponding Author: Dalim K Baidya, Department of Anaesthesiology, Pain Medicine and Critical Care, All India Institute of Medical Sciences, Delhi, India, e-mail: dalimkumar.ab8@gmail.com

How to cite this article: Nath S, Baidya DK. Mucormycosis in COVID-19: Is Zinc a Silent Killer in India? Indian J Crit Care Med 2021;25(9):1079-1080.

Source of support: Nil

Conflict of interest: None

doses of zinc and should exercise measures to prevent uncontrolled availability of zinc tablets over-the-counter in the country.

\section{OrCID}

Sayan Nath @ https://orcid.org/0000-0003-3114-5520

Dalim K Baidya @ https://orcid.org/0000-0001-7811-7039

\section{References}

1. Available at https://www.covid19india.org/ (accessed 23 May 2021).

2. Singh AK, Singh R, Joshi SR, Misra A. Mucormycosis in COVID-19: a systematic review of cases reported worldwide and in India. Diab Metabol Syndr Clin Res Rev. 2021. DOI: 10.1016/j.dsx.2021.05.019.

3. Prakash H, Chakrabarti A. Epidemiology of mucormycosis in India. Microorganisms 2021;9:523. DOI: 10.3390/microorganisms9030523.

4. Gangneux JP, Bougnoux ME, Dannaoui E. Invasive fungal diseases during COVID-19: We should be prepared. J Mycol Med 2020;30(2):100971. DOI: 10.1016/j.mycmed.2020.100971.

5. Thomas S, Patel D, Bittel B. Effect of high-dose zinc and ascorbic acid supplementation vs usual care on symptom length and reduction among ambulatory patients with SARS-CoV-2 infection: the COVID A to Z randomized clinical trial. JAMA Netw Open 2021;4(2):e210369. DOI: 10.1001/jamanetworkopen.2021.0369.

6. COVID-19 Treatment Guidelines Panel. Coronavirus disease 2019 (COVID-19) treatment guidelines. National Institutes of Health. Available at: https://www.covid19treatmentguidelines.nih.gov/ (accessed 23 May 2021).

7. Management protocol for COVID-19. Available at: http://www. wbhealth.gov.in (accessed 23 May 2021).

8. Revised guideline for home isolation/home care of COVID-19 positive patients. Municipal Corporation of Greater Mumbai. Available at: https://www.mumbai.in.emb-japan.go.jp/files/100170201.pdf (accessed 23 May 2021).

9. Wilson D. An evolutionary perspective on zinc uptake by human fungal pathogens. Metallomics 2015;7(6):979-985. DOI: 10.1039/ c4mt00331d.

(c) Jaypee Brothers Medical Publishers. 2021 Open Access This article is distributed under the terms of the Creative Commons Attribution 4.0 International License (https://creativecommons.org/licenses/by-nc/4.0/), which permits unrestricted use, distribution, and non-commercial reproduction in any medium, provided you give appropriate credit to the original author(s) and the source, provide a link to the Creative Commons license, and indicate if changes were made. The Creative Commons Public Domain Dedication waiver (http://creativecommons.org/publicdomain/zero/1.0/) applies to the data made available in this article, unless otherwise stated. 
10. Staats CC, Kmetzsch L, Schrank A, Vainstein MH. Fungal zinc metabolism and its connections to virulence. Front Cell Infect Microbiol 2013;3:65. DOI: 10.3389/fcimb.2013.00065.

11. Lulloff SJ, Hahn BL, Sohnle PG. Fungal susceptibility to zinc deprivation. J Lab Clin Med 2004;144:208-214. DOI: 10.1016/j.lab.2004.07.007.

12. Leonardelli F, Macedo D, Dudiuk C, Theill L, Cabeza MS, Gamarra S, et al. In vitro activity of combinations of zinc chelators with amphotericin $B$ and posaconazole against six mucorales species. Antimicrob Agents Chemother 2019;63(5):e00266. DOI: 10.1128/AAC.00266-19.

13. Cohrt KAO, Marín L, Kjellerup L, Clausen JD, Dalby-Brown W, Calera JA, et al. Novel zinc-attenuating compounds as potent broad-spectrum antifungal agents with in vitro and in vivo efficacy. Antimicrob Agents Chemother 2018;62(5):e02024. DOI: 10.1128/AAC.02024-17. 